\section{BMJ Open Respiratory Research}

\title{
Impact of blood group on survival following critical illness: a single-centre retrospective observational study
}

\author{
Robert Slade, ${ }^{1}$ Raza Alikhan, ${ }^{2}$ Matt P Wise, ${ }^{1}$ Lam Germain, ${ }^{1}$ Simon Stanworth, ${ }^{3}$ \\ Matt Morgan ${ }^{\oplus}$
}

To cite: Slade R, Alikhan $\mathrm{R}$ Wise MP, et al. Impact of blood group on survival following critical illness: a single-centre retrospective observational study. BMJ Open Resp Res 2019;6:e000426. doi:10.1136/ bmjresp-2019-000426

Received 8 March 2019 Revised 13 June 2019 Accepted 17 June 2019
Check for updates

\section{(c) Author(s) (or their} employer(s)) 2019. Re-use permitted under CC BY-NC. No commercial re-use. See rights and permissions. Published by BMJ.

${ }^{1}$ Adult Critical Care, University Hospital of Wales, Cardiff and Vale University Healthcare NHS Trust, Cardiff, UK 2Department of Haematology, University Hospital of Wales, Cardiff and Vale University Healthcare NHS Trust, Cardiff, UK

${ }^{3}$ Departement of Haematology, Oxford University Hospitals NHS Foundation Trust, Oxford, UK

Correspondence to Dr Matt Morgan; mattmorgan@me.com

\section{ABSTRACT}

Background Predicting patient outcomes following critical illness is challenging. Recent evidence has suggested that patients with blood group $A B$ are more likely to survive following major cardiac surgery, and this is associated with a reduced number of blood transfusions. However, there are no current data to indicate whether a patient's blood group affects general intensive care outcomes.

Objective The objective of this study was to determine if $A B O$ blood group affects survival in intensive care. The primary outcome measure was 90-day mortality with a secondary outcome measure of the percentage of patients receiving a blood transfusion.

Design Retrospective analysis of electronically collected intensive care data, blood group and transfusion data. Setting General intensive care unit (ICU) of a major tertiary hospital with both medical and surgical patients. Patients All patients admitted to ICU between 2006 and 2016 who had blood group data available.

\section{Intervention None.}

Measurements and main results 7340 patients were included in the study, blood group $A B$ accounted for $3 \%$ (221), A 41\% (3008), B 10.6\% (775) and $045.4 \%$ (3336). These values are similar to UK averages. Baseline characteristics between the groups were similar. Blood group $A B$ had the greatest survival benefit (blood group $A B$ 90-day survival estimate $76.75,95 \% \mathrm{Cl} 72.89$ to 80.61 with the overall estimate $72.07,95 \% \mathrm{Cl} 71.31$ to 72.82 ) (log-rank $\left.\chi^{2} 16.128, p=0.001\right)$. Transfusion requirements were similar in all groups with no significant difference between the percentages of patients transfused $(A B$ $23.1 \%$, A 21.5\%, B 18.7\%, 0 19.9\%, Pearson $\chi^{2} 5.060$ $\mathrm{p}=0.167)$.

Conclusion Although this is primarily a hypothesis generating study, intensive care patients with blood group $A B$ appeared to have a higher 90-day survival compared with other blood groups. There was no correlation between blood group and percentage of patients receiving transfusion.

\section{INTRODUCTION}

Predicting patient outcomes following critical illness is challenging. Personalised medicine, where a greater understanding of patients' risks from genetic, environmental and social factors is becoming increasingly important and may allow better planning of therapy

\section{Key messages}

Does blood group influence mortality in patients with critical illness?

- Intensive care patients with blood group $A B$ appeared to have a higher 90-day survival compared with other blood groups.

- This is the first study to describe an effect of blood group on survival following critical illness.

and outcomes. ${ }^{1}$ Although genetic variation is known to be one factor in determining survival following admission to intensive care, this can be difficult and costly to assess in clinical practice. ${ }^{1}$

At the onset of critical illness, a logical and pragmatic approach is required to effectively manage patients. $\mathrm{ABO}$ blood group testing is a routine medical test that provides a rapid patient phenotype to the clinician. If $\mathrm{ABO}$ blood group impacts survival, it could provide a useful additional facet to stratifying risk. In addition, it may direct clinicians towards novel therapeutic interventions in the future.

The effect of $\mathrm{ABO}$ group has been analysed in multiple disease pathologies with differences noted in venous thromboembolism, ${ }^{2}$ coronary artery disease ${ }^{3}$ and malignancies including those of the pancreas and stomach. ${ }^{4-6}$ Recent evidence has suggested that patients with blood group $\mathrm{AB}$ are more likely to survive following major cardiac surgery and this is associated with a reduced number of blood transfusions. ${ }^{7}$ There may also be an influence on patient outcomes according to the gender and age of transfused products. ${ }^{1}$

There is a body of evidence which demonstrates that blood group $\mathrm{AB}$ has higher levels of von Willebrand factor ( $\mathrm{vWF}$ ) and factor VIII, ${ }^{9}$ making this group more pro-thrombotic. While this may increase the risk of both arterial and venous thrombotic events, ${ }^{10}{ }^{11}$ it may be beneficial in patient groups where 


\begin{tabular}{|c|c|c|}
\hline Group & $\%$ in study & $\%$ in UK \\
\hline$A$ & 40.9 & 42 \\
\hline$A B$ & 3 & 4 \\
\hline B & 10.6 & 10 \\
\hline $\mathrm{O}$ & 45.4 & 44 \\
\hline
\end{tabular}

bleeding risks are high. In one study of more than 1100 healthy volunteers, mean $\mathrm{vWF}$ antigen was lowest in blood group $\mathrm{O}(74.8 \mathrm{U} / \mathrm{dL})$, followed by blood group A $(105.9 \mathrm{U} / \mathrm{dL})$, group $\mathrm{B}(116.9 \mathrm{U} / \mathrm{dL})$ and finally group $\mathrm{AB}(123.3 \mathrm{U} / \mathrm{dL}) .{ }^{12}$ This increases the rate of significant bleeding in group $\mathrm{O}$ patients most notably in surgical procedures with a high risk of blood loss. ${ }^{13}$

Currently, there are no available data to indicate whether a patient's blood group affects general intensive care outcomes.

The objective of the study was to determine if $\mathrm{ABO}$ blood group affects survival following admission to a general intensive care unit (ICU). The primary outcome measure was 90 -day mortality with a secondary outcome measure of the percentage of patients receiving a blood transfusion during that hospital admission.

\section{MATERIALS AND METHODS}

We performed a retrospective database analysis of all patients admitted to the ICU of a major tertiary University Hospital (both medical and surgical patients) between 2006 and 2016 where ABO blood group data were available. Baseline characteristics for each blood group were collected including, age, gender, body mass index (BMI), surgery during admission, days in hospital, ethnicity and APACHE II score. Continuous baseline characteristics were evaluated using analysis of variance (ANOVA). A $\chi^{2}$ test was used to determine equivalence of baseline characteristics of discrete variables.

Patients' primary ABO blood group status was collected along with any blood product transfusions they received during their hospital stay.
The primary outcome for the study was 90-day hospital survival. Survival analysis was performed using the time from hospital admission to discharge. If patients had a hospital stay longer than 90 days, data were censored to 90 days. The secondary outcome measure was the percentage of each blood group that received any blood product transfusion.

Ninety-day survival was estimated by Kaplan-Meier plots, with binary logistic regression used to calculate odds ratios between different blood groups. Binary logistic regression with Pearson's $\chi^{2}$ test was used to determine OR between blood groups. ABO blood groups were individually compared and then pooled to compare $A B$ versus non- $A B$ blood groups. A subgroup analysis was performed on patients that had surgery during their admission.

Intensive care data were merged with individual patient transfusion data using R (V.1.0.136, 2016, R Studio). The combined data were exported to SPSS (V.23.0, IBM) for statistical evaluation. The study was granted scientific approval by Wales research ethics review service.

\section{Patient and public involvement}

As this was a retrospective database study, there was no individual patient or public involvement. However, it does conform with the James Lind top ten priority setting from public groups including 'How can we predict who will benefit from intensive care before admission and during treatment in the ICU?'

\section{RESULTS}

During January 2010 to January 2016, 7906 patients were admitted to the ICU with blood group data available for 7340. Blood group $\mathrm{AB}$ accounted for $3 \%$ (221), A $41 \%$ (3008), B $10.6 \%$ (775) and O $45.4 \%$ (3336). These values are similar to UK averages. The mean age was $58.8 \pm 17.2$ years; $41.7 \%$ of patients $(\mathrm{n}=3063)$ were female and average BMI was $27.05 \pm 6.4$ (table 1). Admission APACHE score was $13.45 \pm 7.86$ and the percentage of patients undergoing surgery during their admission was $46.3 \%(\mathrm{n}=3399)$. Baseline characteristics were statistically

\begin{tabular}{|c|c|c|c|c|c|c|}
\hline Characteristic & Overall & A & AB & B & 0 & $P$ value \\
\hline Number (\%) & $n=7340$ & $3008(41.0 \%)$ & $221(3.0 \%)$ & $775(10.6 \%)$ & $3336(45.4 \%)$ & - \\
\hline Mean age, years (SD) & $58.8(17.2)$ & $59.3(17.1)$ & $58(16.6)$ & $58.8(17.3)$ & $58.5(17.3)$ & 0.245 \\
\hline Female, \% (n) & $41.7 \%(3063)$ & $41.7 \%(1255)$ & $36.2 \%(80)$ & $43.7 \%(339)$ & $41.7 \%(3063)$ & 0.508 \\
\hline BMI, mean (SD) & $27.05(6.4)$ & $27.1(6.3)$ & $26.8(6.8)$ & $27(7.2)$ & $27.1(6.2)$ & 0.894 \\
\hline Surgery during admission, \% (n) & $46.3 \%$ (3399) & $46.5 \%(1398)$ & $41.6 \%(92)$ & $44.6 \%(346)$ & $46.9 \%(1563)$ & 0.356 \\
\hline Days in hospital, mean (SD) & $30.2(45.2)$ & $31.5(53.0)$ & $29.0(28.1)$ & $28.2(37.2)$ & 29.6 (39.9) & 0.202 \\
\hline$\%$ Caucasian (n) & $95.5 \%(7013)$ & $97.1 \%(2922)$ & $95.5 \%(211)$ & $90.3 \%(700)$ & $95.3 \%(3180)$ & 0.000 \\
\hline APACHE score, mean (SD) & $13.45(7.86)$ & $13.59(7.87)$ & $13.39(7.62)$ & $13.52(8.26)$ & $13.30(7.77)$ & 0.528 \\
\hline
\end{tabular}

BMI, body mass index. 


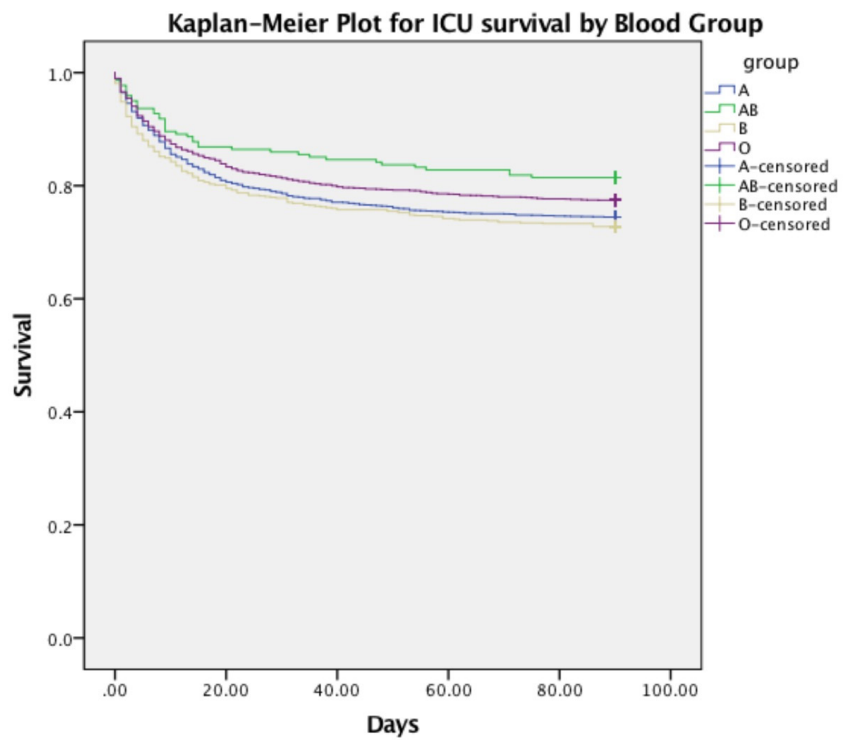

Figure 1 Kaplan-Meier survival plot for 90-day intensive care unit survival by $\mathrm{ABO}$ blood group.

similar across the blood groups except for the ethnicity of the groups with blood group B having fewer Caucasians $90.3 \%$ compared with an average of $95.5 \%$ (table 2).

Blood group $\mathrm{AB}$ had the greatest survival difference when assessing individual blood groups (figure 1) (blood group AB 90-day survival estimate $76.75,95 \%$ CI 72.89 to 80.61 with the overall estimate $72.07,95 \%$ CI 71.31 to 72.82) (log-rank $\left.\chi^{2} 16.128, p=0.001\right)$.

When pooling blood group data (figure 2), KaplanMeier analysis showed blood group $\mathrm{AB}(\mathrm{n}=221)$ to have improved survival compared with non- $\mathrm{AB}$ blood groups $(\mathrm{n}=7119) \quad$ (blood group $\mathrm{AB}$ 90-day survival estimate $76.75,95 \%$ CI 72.89 to 80.61 non-AB groups $71.92,95 \%$ CI 71.15 to 72.69$)\left(\log -\operatorname{rank} \chi^{2} 3.890, \mathrm{p}=0.049\right)$.

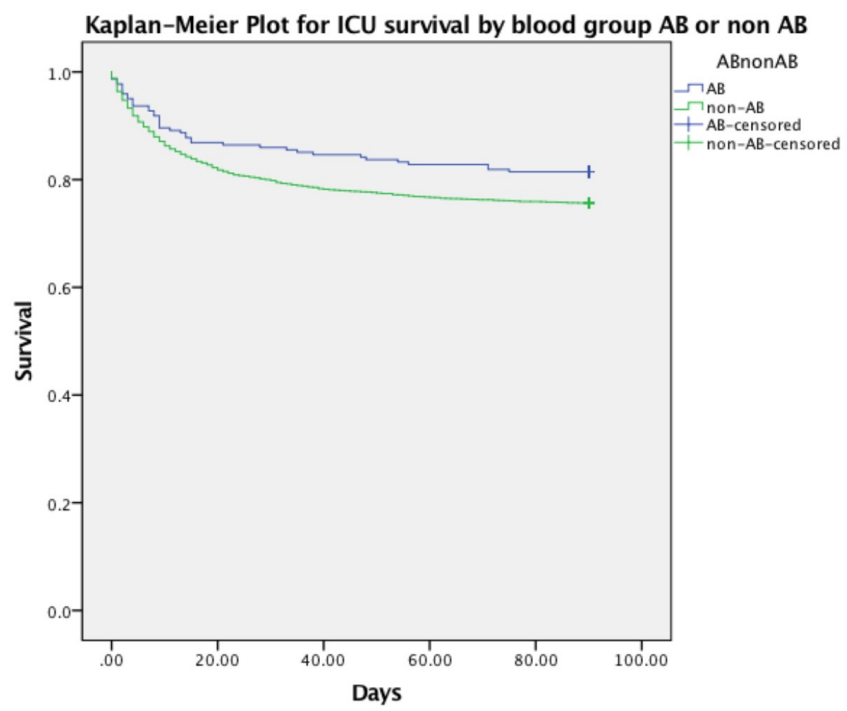

Figure 2 Kaplan-Meier survival plot for 90-day intensive care unit survival for $A B$ compared with pooled non-AB blood groups.

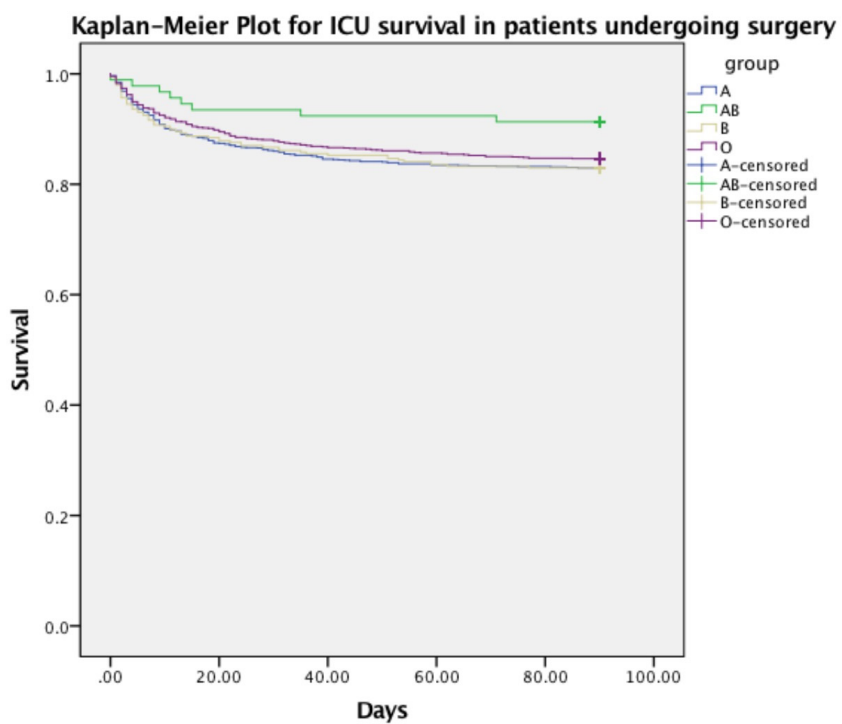

Figure 3 Kaplan-Meier survival plot for 90-day ICU survival by $A B O$ blood group in subgroup of patients undergoing surgery during admission.

Compared with $\mathrm{AB}$, non- $\mathrm{AB}$ groups had an $\mathrm{OR}$ for death of 1.413 (95\% CI 1.002 to 1.992, $\mathrm{p}=0.049$ ). Blood group $\mathrm{AB}$ also showed a trend towards improved 90-day survival in the subgroup ( $\mathrm{n}=3399)$ of patients who underwent surgery during their hospital admission (figure 3) (blood group $\mathrm{AB} 83.89,95 \%$ CI 79.64 to 88.14 with the overall estimate $78.26,95 \%$ CI 77.32 to 79.20 ), however this benefit was not statistically significant (log-rank $\chi^{2}$ $5.537, \mathrm{p}=0.136)$.

Transfusion requirements were similar in all groups (table 3) with no significant difference between the percentages of patients transfused (AB 23.1\%, A 21.5\%, B $18.7 \%$, O 19.9\%, Pearson $\chi^{2} 5.060$ p=0.167).

\section{DISCUSSION}

This is the first study to describe an effect of blood group on survival following critical illness. We observed patients with blood group $\mathrm{AB}$ to have an improved 90-day survival following admission to the ICU.

$\mathrm{ABO}$ blood group system is the major component of categorising a patients' blood type. The ABO blood group system was first described by Landsteiner in 1900; despite more than 300 antigens identified on red blood cells (RBC), the ABO blood group system remains the

\begin{tabular}{ll}
\hline Table 3 & Transfusion requirements per blood group \\
\hline Group & $\begin{array}{l}\text { \% of blood group transfused } \\
\text { (n) }\end{array}$ \\
\hline A & $21.5(648)$ \\
AB & $23.1(51)$ \\
B & $18.7(145)$ \\
O & $19.9(665)$ \\
Total & $20.6(1509)$ \\
\hline
\end{tabular}


most significant in cases of mismatch. ${ }^{14}$ The ABO system of blood grouping refers to antibodies against glycopeptide antigens present on RBC, and other cells including sensory neurons, platelets and endothelium. ${ }^{15}$ An isolated gene on chromosome 9 at the loci 9q34.1-q34.2 determines ABO blood group. ${ }^{16} 17$ This locus encodes a glycosyltransferase that produces $\mathrm{N}$-acetylgalactosamine (A antigen) and D-galactose (B antigen) for the surface of the RBC. ${ }^{8}$ These antigens are formed from a precursor antigen $\mathrm{H}$ encoded on chromosome 19 (loci 19q13.3). ${ }^{8}$ The immune system then forms antibodies against the ABO blood group antigens not found in the individual.

$\mathrm{ABO}$ blood group has been implicated as a risk factor in both venous thromboembolism ${ }^{2}$ and coronary artery disease. ${ }^{3}$ One proposed mechanism for the varying clinical outcomes in patients is the different amounts of vWF and factor VIII per blood group. ABO blood group plays an important role in determining levels of vWF and factor VIII in the circulation. ${ }^{18} \mathrm{vWF}$ is an adhesive glycoprotein which acts as a key haemostatic agent by binding with structures involved in the coagulation cascade particularly factor VIII, exposed collagen and platelets. ${ }^{19}$ It is known that factor VIII levels are primarily affected by vWF as the two form a complex where vWF is the carrier, however recent evidence has shown that ABO blood group has an additional effect on Factor VIII levels which is independent to $\mathrm{vWF}^{9}$

Individual levels of vWF vary widely. Blood group $\mathrm{O}$ demonstrate lower levels of $\mathrm{vWF}$ and factor VIII and this is thought to have a functional effect on thrombosis with a reduced risk. ${ }^{20}$ Higher levels of factor VIII and vWF are associated with higher levels of venous thromboembolism and arterial disease, particularly myocardial infarction. $^{21}$ Blood group O levels of vWF are up to $25 \%$ lower than non-O blood groups. ${ }^{21} 22$ Among the non-O blood groups, blood group $\mathrm{AB}$ has the highest levels of $\mathrm{vWF}^{23}$ Blood group $\mathrm{AB}$ may therefore represent a higher risk for thrombosis under normal conditions, however this may lead to a survival benefit under periods of physiological stress such as surgery or critical illness where a prothrombotic state is potentially beneficial.

There are a number of limitations to the current study. The data available in this retrospective analysis did not allow us to perform covariate adjusted analysis using pre-existing conditions, critical care management or specific reasons for current admission. This is a constraint in an observational study of this type which may be addressed in future studies with more comprehensive datasets.

We hypothesised that survival of blood group $A B$ patients may be related to levels of vWF/Factor VII but these were not measured. There was no statistical difference in the numbers of patients receiving blood transfusion in any of the groups, however we do not know if there were differences in the number of units transfused or indeed other blood products. It is also possible that the number of patients in our study was too small to detect a difference in transfusion requirements. This is in contrast to patients undergoing cardiac surgery, ${ }^{7}$ as this population of patients is more likely to receive blood transfusions and therefore differences may be more evident. The relevance of $\mathrm{vWF} / \mathrm{FVII}$ in modulating the observed association is only speculative and other mechanisms are described in the literature. ${ }^{24}$

The retrospective study design limits the conclusions we can draw from this study, as we can suggest there is an association between survival and $\mathrm{AB}$ blood group but no causation. In addition, using a 90-day measure for survival means we cannot draw long-term outcomes from our study.

This is the first study to assess the effects of blood group on patients with critical illness. This work supports the findings of Welsby et al that patients with blood group $\mathrm{AB}$ are more likely to survive cardiac surgery. ${ }^{7}$ There are a number of overlaps between the two population groups, however our population was in a general ICU setting. As such there was a greater variety of aetiologies of critical illness with both medical and surgical cohorts of patients included. A subgroup analysis showed that surgical patients in the ICU had a greater survival benefit of being blood group $\mathrm{AB}$, however this was not statistically significant.

Our study used 10 year data at a single centre. The patients included in our study was representative of the distribution of $\mathrm{ABO}$ blood groups within the UK, blood group $\mathrm{AB}$ is a relatively small proportion accounting for $3 \%$ in our study $(n=221)$ and across the $U K{ }^{25}$ It is also important to highlight that we compared results based on the phenotype of patients not their individual blood group genotype. This is in keeping with clinical practice and the literature on $\mathrm{ABO}$ blood group and clinical outcomes.

It is likely that there are a wide variety of genetic factors that are interlinked that help to determine an individual's outcome from disease. However, it can be difficult to elicit an individual patient's genetic risk, particularly within clinical practice. ABO blood typing is a ubiquitous clinical test that provides a window onto the genetic nature of disease and variations in patient outcome. It seems likely that ABO blood group is interlinked with other genetic and patient factors to determine differences in prevalence and outcome from varying disease pathologies. Future studies could measure vWF/FVII in different blood groups and a future therapeutic intervention based on mechanistic studies may include targeted transfusion or use of drugs such as desmopressin.

\section{CONCLUSIONS}

Intensive care patients with blood group $\mathrm{AB}$ have a significantly higher 90-day survival compared with other blood groups. There was no correlation between blood group and percentage of patients receiving transfusion. Blood group $\mathrm{AB}$ is relatively rare accounting for $3 \%$ of the study population and therefore our study may have been underpowered to determine this bleeding risk. Improved 
survival outcomes in blood group $\mathrm{AB}$ are a promising area for further study.

Acknowledgements We extend our thanks to Blood Bank at University Hospital of Wales for their help with extraction of blood group and transfusion data.

Contributors MM and RS conceived of the presented idea and developed the theory. LG and RD collected the data. RS performed many of the computations. RA, MPW and SS verified the analytical methods. All authors discussed the results and contributed to the final manuscript.

Funding Study carried out at the University Hospital of Wales Critical Care Directorate.

Competing interests None declared.

Patient consent for publication Not required.

Ethics approval Welsh Research Ethics Committee reference 16/WA/0207.

Provenance and peer review Not commissioned; externally peer reviewed.

Data availability statement Data are available upon reasonable request.

Open access This is an open access article distributed in accordance with the Creative Commons Attribution Non Commercial (CC BY-NC 4.0) license, which permits others to distribute, remix, adapt, build upon this work non-commercially, and license their derivative works on different terms, provided the original work is properly cited, appropriate credit is given, any changes made indicated, and the use is non-commercial. See: http://creativecommons.org/licenses/by-nc/4.0/.

\section{REFERENCES}

1. Maslove DM, Lamontagne F, Marshall JC, et al. A path to precision in the ICU. Critical Care 2017;21.

2. Tsai AW, Cushman M, Rosamond WD, et al. Coagulation factors, inflammation markers, and venous thromboembolism: the longitudinal investigation of thromboembolism etiology (Lite). The American Journal of Medicine 2002;113:636-42.

3. Chen Z, Yang S-H, Xu H, et al. ABO blood group system and the coronary artery disease: an updated systematic review and metaanalysis. Scientific Reports 2016;6.

4. Wolpin BM, Chan AT, Hartge P, et al. ABO blood group and the risk of pancreatic cancer. J Natl Cancer Inst 2009;101:424-31.

5. Li B, Tan B, Chen C, et al. Association between the ABO blood group and risk of common cancers. J Evid based Med. John Wiley \& Sons, Ltd 2014;7:79-83.

6. Y-Q X, Jiang T-W, Cui Y-H, et al. Prognostic value of ABO blood group in patients with gastric cancer. J Surg Res 2016;201:188-95.

7. Welsby IJ, Phillips-Bute B, Mathew JP, et al. ABO blood group influences transfusion and survival after cardiac surgery. J Thromb Thrombolysis 2014;38:402-8.
8. Franchini M, Capra F, Targher G, et al. Relationship between ABO blood group and von Willebrand factor levels: from biology to clinical implications. Thrombosis Journal 2007;5.

9. Song J, Chen F, Campos M, et al. Quantitative influence of ABO blood groups on factor VIII and its ratio to von Willebrand factor, novel observations from an ARIC study of 11,673 subjects. Plos One 2015;10:e0132626

10. Meade TW, Cooper JA, Stirling Y, et al. Factor VIII, ABO blood group and the incidence of ischaemic heart disease. $\mathrm{Br} J$ Haematol 1994;88:601-7.

11. Spiezia L, Campello E, Bon M, et al. ABO blood groups and the risk of venous thrombosis in patients with inherited thrombophilia. Blood Transfus 2013;11:250-3.

12. Castaman G, Eikenboom JCJ. ABO blood group also influences the von Willebrand factor (vWF) antigen level in heterozygous carriers of vWF null alleles, type $2 n$ mutation Arg854GIn, and the missense mutation Cys2362Phe. Blood 2002;100:1927-8.

13. Franchini M, Lippi G. Relative risks of thrombosis and bleeding in different ABO blood groups. Semin Thromb Hemost. Thieme Medical Publishers 2016;42:112-7.

14. Jenkins PV, O'Donnell JS. ABO blood group determines plasma von Willebrand factor levels: a biologic function after all? Transfusion 2006;46:1836-44.

15. Eastlund T. The histo-blood group ABO system and tissue transplantation. Transfusion 1998;38:975-88.

16. Pratt V, McLeod H, Rubinstein W, et al. ABO blood group. Bethesda (MD: National Center for Biotechnology Information (US), 2012.

17. Yamamoto F, Yamamoto M. Molecular genetic basis of porcine histoblood group AO system. Blood 2001;97:3308-10.

18. O'Donnell J, Laffan MA. The relationship between ABO histoblood group, factor VIII and von Willebrand factor. Transfus Med 2001:11:343-51.

19. Peyvandi F, Garagiola I, Baronciani L. Role of von Willebrand factor in the haemostasis. Blood Transfus 2011;9(Suppl 2):s3-8.

20. Souto JC, Almasy L, Muñiz-Diaz E, et al. Functional effects of the $\mathrm{ABO}$ locus polymorphism on plasma levels of von Willebrand factor, factor VIII, and activated partial thromboplastin time. Arterioscler Thromb Vasc Biol 2000;20:2024-8.

21. Orstavik KH, Magnus P, Reisner $\mathrm{H}$, et al. Factor VIII and factor IX in a twin population. Evidence for a major effect of $A B O$ locus on factor VIII level. Am J Hum Genet. Elsevier 1985;37:89-101.

22. Notarnicola A, Pesce V, Maccagnano G, et al. Klippel-Trenaunay syndrome: a rare cause of disabling pain after a femoral fracture. Arch Orthop trauma Surg. Springer-Verlag 2012;132:993-6.

23. Gill JC, Endres-Brooks J, Bauer PJ, et al. The effect of ABO blood group on the diagnosis of von Willebrand disease. Blood 1987;69:1691-5.

24. Mohlke KL, Ginsburg D. Von Willebrand disease and quantitative variation in von Willebrand factor. J Lab Clin Med 1997;130:252-61.

25. De Gruchy GC. Clinical haematology in medical practice. . 5th edn. Wiley-Blackwell, 2008: 1. 46. 